Tempo Social; Rev. Sociol. USP, S. Paulo, 7(1-2): 53-66, outubro de 1995.

\title{
Foucault e a noção de acontecimento
}

\author{
IRENE DE ARRUDA RIBEIRO CARDOSO
}

\begin{abstract}
RESUMO: A partir das últimas obras de Foucault, procuro analisar a importância do seu trabalho sobre uma história do pensamento, em que a noção de acontecimento é central. Articulada às noções de atualidade e de problematização constitui o modo como Foucault tematizará o que chama de uma ontologia do presente. A partir de Kant caracteriza o ethos filosófico da crítica do presente, inserindose, de uma maneira específica, nesta tradição. Definindo a problematização da atualidade como uma reativação da questão da Aufklärung, faz desta um acontecimento que nos questiona, enquanto possibilidade de constituição de nós mesmos, como sujeitos autônomos. A interrogação sobre os limites do presente e a possibilidade de sua transgressão instaura um campo problemático do pensamento, na tematização das questões da autonomia e da liberdade. É a partir desse campo que formula a sua interrogação sobre os gregos da Grécia clássica, a questão da ética, como um tipo de relação que determina como o indivíduo se constitui como sujeito moral de suas próprias ações.
\end{abstract}

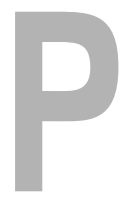

rocurarei, a partir da análise das últimas obras de Foucault "O que é o Iluminismo" (Foucault, 1984c; 1988) e História da Sexualida de II - O Uso dos Prazeres (Foucault, 1984a ), destacar o que ele chama de sua escolha filosófica de um pensamento crítico que toma a forma de uma ontologia da atualidade. Referindo-se ao que considera as duas grandes tradições críticas fundadas por Kant, a de uma "filosofia crítica que se apresentará como uma filosofia analítica da verdade em geral" e a de "um pensamento crítico que tomará a forma de uma ontologia de nós mesmos, de uma ontologia da atualidade", inscreve-se na segunda tradição, que se caracteriza pela interrogação crítica "O que é a nossa atuali-
UNITERMIOS: acontecimento, história, atualidade, problematização, presente, liberdade.

Professora do Departamento de Sociologia da FFCHUSP 
dade? Qual é o campo atual das experiências possíveis?” Uma “ontologia do presente; uma ontologia de nós mesmos”(Foucault, 1984c, p.111-112).

No que se refere à questão do cuidado ético entre os gregos questiona “por que essa 'problematização', afirmando que "esta é a tarefa de uma história do pensamento por oposição à história dos comportamentos ou das representações". Trata-se de "definir as condições nas quais o ser humano "problematiza' o que ele é e o mundo no qual ele vive" - a sua atualidade (Foucault, 1984a, p. 14).

Enfocar o mundo grego desse modo significa que a história do pensamento é construída a partir da tradição crítica na qual Foucault se inscreve, de uma ontologia da atualidade, que problematiza a Grécia clássica, não como "valor exemplar", nem como "algo ao qual retroceder". Mas entendendo que "entre as invenções culturais da humanidade, há as que constituem ou ajudam a constituir um certo ponto de vista que pode ser muito útil como uma ferramenta para analisar o que está acontecendo agora - e modificá-lo" (Foucault, 1984e, p. 47-49). Essa problematização de um cuidado ético como um "tipo de relação que você deve ter consigo próprio, rapport à soi, (...) e que determina como o indivíduo se constitui como sujeito moral de suas próprias ações", a partir de um domínio de si, constróise a partir de uma questão atual, a da problemática das liberações, da liberdade. Essa problemática, por sua vez, está inscrita na tradição kantiana da Aufklärung, "inscrita desde o século XVIII em nosso pensamento". Essa tradição caracteriza "o ethos filosófico presente na crítica ontológica de nós mesmos como uma prova histórico-prática dos limites que podemos ultrapassar e desta maneira como um trabalho levado a cabo por nós mesmos, sobre nós mesmos, como seres livres" (Foucault, 1984e, p. 51 ; 1988, p. 301) . Num texto bem anterior, de 1978, Foucault, tematizando "o que é a crítica" e inscrevendo-a na tradição kantiana afirmava que é possível interrogar os gregos "sem nenhum anacronismo, mas a partir de um problema que é e que foi em todo caso percebido por Kant como sendo um problema de Aufklärung. (...) Não se trata de dizer que os gregos do século V são um pouco como os filósofos do século XVIII (...) mas sim de tentar ver sob quais condições, ao preço de quais modificações ou de quais generalizações podemos aplicar, não importa a qual momento da história, esta questão da Aufklärung [no registro das preocupações desse texto] das relações dos poderes, da verdade e do sujeito" (Foucault, 1990, p. 58, 46, 47).

A questão colocada por Foucault "o que é a nossa atualidade?" tem como implicação tomar a noção de acontecimento como constitutiva desta interrogação. Interrogar a atualidade é questioná-la como acontecimento na forma de uma problematização.

Este tipo de interrogação define o campo das preocupações filosóficas de Foucault, nas últimas obras, embora possamos já encontrar essa tematização em textos anteriores que já o enunciam: "Qu'est-ce que la critique? [Critique et Aufklärung] de 1978 (Foucault, 1990) e La vie: 
l'expérience et la science publicado em 1985, mas que se constitui em pequena modificação da Introdução à edição norte-americana do $O$ normal e patológico, de Canguilhem, em 1978 (Foucault, 1985b).

É preciso dizer ainda que as noções de acontecimento, de problematização e de atualidade, já estavam presentes em suas análises anteriores. Em A arqueologia do Saber, de 1969 (Foucault, 1972, p. 152) e Nietzsche, a genealogia e a história, de 1971 (Foucault, 1979, p. 28) a noção de acontecimento é central como a irrupção de uma singularidade única e aguda, no lugar e no momento da sua produção. Em A arqueologia do saber, ainda, a noção de atualidade, que se diferencia da de presente, aparece como a "borda do tempo que envolve nosso presente, que o domina e que o indica em sua alteridade" (1972, p. 162-163). A noção de problematização é considerada por Foucault como "forma comum aos seus estudos" desde a História da Loucura. Alerta, no entanto, que se deveria considerar "isto com cuidado" pois não havia ainda isolado suficientemente esta noção (Foucault, 1984b, p. 76).

No entanto, a grande novidade das últimas obras é que Foucault explicitamente se inscreve no que considera a tradição crítica herdeira de Kant, a de uma ontologia da atualidade: "forma de filosofia que de Hegel à Escola de Frankfurt, passando por Nietzsche e Max Weber, fundou uma forma de reflexão" dentro da qual tentou trabalhar - embora essa referência também já estivesse enunciada no texto de 1978 (Foucault, 1984c, p. 112 ; 1990, p. 43-46). Além disso a sua preocupação filosófica está construída, ainda, por uma interrogação sobre a atualidade como acontecimento. Diferenciando a atualidade, do presente, é o acontecimento que constrói a interrogação sobre o que somos, na perspectiva dos "limites contemporâneos do necessário, isto é, para aquilo que não é, ou já não é, indispensável para a constituição de nós mesmos, como sujeitos autônomos": a problematização (Foucault, 1988, p. 298).

Procurarei, na medida do possível, caracterizar a partir dos seus últimos textos, a noção de atualidade e a noção de acontecimento; tentarei ainda explicitar por que interrogar a atualidade é problematizá-la como acontecimento e nestes dois movimentos de análise extrair elementos para pensar a concepção de temporalidade histórica que está implicada na utilização dessas noções. Considero relevante nessa concepção, uma influência heideggeriana, no que se refere ao modo como a historicidade está sendo tematizada. Esta referência não se constitui como arbitrária pois se revela a partir da análise dos textos antes referidos. Não é arbitrária, ainda, porque Foucault, embora tenha afirmado que nunca tivesse escrito sobre Heidegger, afirma também que ao lado de Nietzsche, estes se constituíram nas suas "duas experiências fundamentais". "Todo o meu devir filosófico foi determinado por minha leitura de Heidegger (...) é importante ter um pequeno número de autores com os quais se pensa, com os quais se trabalha, mas sobre os quais não se escreve" (...) que se constituem em "instrumentos de 
pensamento'" (Foucault, 1984d, p. 134-135).

As questões que Foucault formula sobre a atualidade revelam a importância atribuída a essas noções e simultaneamente a diferenciação que estabelece entre elas (Foucault, 1984c ;1988). A noção de atualidade não é idêntica à noção de presente mas é construída a partir de um certo tipo de temporalização deste.

Referindo-se ao texto de Kant, $O$ que é o Iluminismo, que teria feito surgir um novo tipo de questão no campo da reflexão filosófica concernente à história, formula a sua problematização: "A questão que me parece surgir pela primeira vez neste texto de Kant é a questão do presente, a questão da atualidade: que é que se passa hoje? Que é que se passa agora? E o que é este 'agora', no interior do qual estamos uns e outros; e quem define o momento em que escrevo" (Foucault, 1984c, p. 103) ${ }^{1}$. "A questão tem por objeto o que é este presente, tem por objeto inicialmente a determinação de um certo elemento do presente que se trata de reconhecer, de distinguir entre todos os outros. O que é que, no presente, faz sentido atualmente para uma reflexão filosófica" (p. 104)2.

Em Qué es la Ilustración? (Foucault, 1988) considera o texto de Kant como estando na "encruzilhada da reflexão crítica e da reflexão histórica": uma reflexão de Kant sobre o "status contemporâneo de sua própria iniciativa". Uma "reflexão sobre a história e uma análise particular do momento específico no qual escreve e por que escreve". Uma reflexão sobre "o presente como diferença histórica", "motivo para uma particular tarefa filosófica", que se constituiria numa grande novidade (Foucault, 1988, p. 294).

Há uma distinção portanto entre o presente e o atual, entre o hoje e o agora. $\mathrm{O}$ atual é construído a partir de um "certo elemento do presente que se trata de reconhecer", como "diferença histórica". Este reconhecimento, que é o da crítica, da problematização, desatualiza o presente, desatualiza o hoje, no movimento de uma interpelação. Nesse sentido o presente não é dado, nem enquadrado numa linearidade entre o passado e o futuro. Mas enquanto atualidade, no movimento de uma temporalização, o que somos é simultaneamente a expressão de uma força que já se instalou e que continua atuante, na expressão heideggeriana, do "vigor de ter sido presente" e o que nos tornamos, o que estamos nos tornando, enquanto abertura para um campo de possibilidades (cf. Heidegger, 1990, p. 186192).

Assim é que a atualidade é atualização e porvir mas também desatualização do hoje. Diante da questão "O que é Aufklärung", a interrogação sobre a atualidade, não supõe uma manutenção fiel aos "elementos doutrinários", mas como atualização se trata antes de uma "reativação permanente de uma atitude; isto é [de] um ethos filosófico que poderia descre-

${ }^{1}$ Destaques meus.

${ }^{2}$ Destaques meus. ver-se como uma crítica permanente de nossa era" (Foucault, 1988, p. 298). A questão portanto não é a de retrospectivamente orientar-se para o "miolo 
essencial da racionalidade", que se pode encontrar na Aufklärung, mas para os "limites contemporâneos do necessário, isto é, para aquilo que não é ou já não é indispensável para a constituição de nós mesmos como sujeitos autônomos" (p. 298). O movimento de atualização é também porvir pois a interrogação sobre a atualidade é uma "atitude limite": "devemos nos mover mais além das alternativas internas e externas; colocando-nos na fronteira" (...) no ponto de uma "transgressão possível" (Foucault, 1988, p. 300).

A interrogação sobre "o que é a nossa atualidade" supondo o movimento de atualização e porvir constitui-se numa crítica do presente, e nesse sentido, desatualizando o hoje, re-inscreve, através da reativação permanente de uma certa atitude referente a Aufklärung, algo, "que permanece nos enfrentando" (Heidegger, 1964, p. 224).

Talvez, a partir dessas considerações, seja possível indicar em que termos Foucault vai considerar, a partir de Kant, que a Aufklärung e a Revolução Francesa constituíram-se como "acontecimentos que não se podem mais esquecer": quando a "constituição política escolhida à vontade pelos homens e uma constituição política que evita a guerra são o processo mesmo da Aufklärung" (Foucault, 1984c, p. 110).

Pode-se indicar como Foucault, a partir de Kant entende que a filosofia pela primeira vez problematiza sua própria "atualidade discursiva: atualidade que ela questiona como acontecimento, como um acontecimento do qual ela pode dizer o sentido, o valor, a singularidade filosófica" (Foucault, 1984c, p. 104). "O que é Aufklärung, o que é a Revolução, são as duas formas sob as quais Kant colocou a questão da sua própria atualidade. São também creio, as duas questões que não cessaram de perseguir senão toda a filosofia moderna, desde o século XIX, pelo menos grande parte desta filosofia". A Aufklärung "não é simplesmente para nós um episódio na história das idéias. Ela é uma questão filosófica inscrita desde o século XVIII em nosso pensamento. Deixemos à sua devoção aqueles que querem que se guarde viva e intacta a herança da Aufklärung. Esta devoção é certamente a mais comovedora das traições. Não são os restos da Aufklärung que se trata de preservar; é a questão mesma deste acontecimento e do seu sentido (a questão da historicidade do pensamento universal) que é preciso manter presente e guardar no espírito como aquilo que deve ser pensado" (Foucault, 1984c, p. 111).

Essas afirmações de Foucault permitem entender que "O que é a Aufklärung e O que é a Revolução" constituem-se no modo como Kant interpelou a sua própria atualidade, em questões reativadas desde o século XVIII e inscritas no pensamento de nossa atualidade. A herança da Aufklärung e da Revolução Francesa não se configura como um "passado simplesmente dado". Mas essas questões enquanto revelação de um acontecimento e do sentido desse acontecimento devem ser mantidas presentes como aquilo que deve ser pensado. A reativação e a manutenção da presença dessas duas questões concernem à sua atualização - à sua re-inscrição 
permanente no pensamento desde o século XVIII até o presente. Manter presente o acontecimento é impe-dí-lo de se dissipar na dispersão do tempo, no esquecimento, é guardá-lo no espírito como aquilo que deve ser pensado. É a manutenção de uma memória como o re-colher do já pensado memória como pensamento sobre aquilo que foi pensado, no sentido ainda, de aguardar o não pensado que aí se esconde. (cf. Heidegger, 1990, p. 220; 1966, p. 161, 165; Foucault, 1972, p. 153-155).

É nesse contexto que podemos compreender que para Foucault "a questão para a filosofia não é determinar qual a parte da revolução que conviria preservar e fazer valer como modelo. É preciso saber o que é preciso fazer desta vontade de revolução, deste 'entusiasmo' pela Revolução que é outra coisa que o empreendimento revolucionário. As duas perguntas 'Que é Aufklärung' e ‘que fazer da vontade de Revolução' definem sozinhas o campo da interrogação filosófica que concerne àquilo que somos em nossa atualidade" (Foucault, 1984c, p. 111).

É a partir daí que fazem sentido as interrogações de Foucault: "O que é a nossa atualidade? Qual o campo atual das experiências possíveis?"

Nessa direção, ainda, é possível compreender a interpretação que Foucault faz da problematização de Kant sobre o entusiasmo pela Revolução Francesa como acontecimento, signo de uma disposição moral da humanidade, que se manifesta permanentemente sob dois aspectos: o direito que um povo tem de elaborar independentemente sua constituição e o princípio conforme ao direito e à moral de uma constituição política tal que evite toda guerra ofensiva. Este signo é rememorativum porque "revela esta disposição presente desde a origem"; demonstrativum porque "mostra a eficácia presente desta disposição"; prognosticum, "pois se há muitos resultados da Revolução que podem ser colocados em questão, não se pode esquecer a disposição que se revelou através dela" (Foucault, 1984c, p. 109). Nesse sentido a Revolução como acontecimento é uma "virtualidade permanente e que não pode ser esquecida" (p. 110). Nos três registros apontados trata-se da presença ou da manutenção da presença (o não esquecimento) dessa disposição como um acontecimento-signo, seja como reativação ou projeção na história.

Esta concepção de Foucault sobre o acontecimento Revolução Francesa e Aufklärung, como aquilo que se constitui através da problematização que Kant faz de sua própria atualidade, é também algo que se inscreve no pensamento da modernidade e se coloca para a nossa atualidade como alguma coisa que nos concerne - enquanto possibilidade de “constituição de nós mesmos como sujeitos autônomos" (Foucault, 1988, p. 298).

Neste movimento há uma temporalização do acontecimento que indica uma certa concepção de historicidade. Como diz Foucault, não se trata de tomar a Aufklärung enquanto um "miolo essencial da racionalidade", enquanto herança guardada viva e intacta, ou ainda, enquanto preservação 
dos seus restos. Não se trata também de considerar a Revolução Francesa como o Grande Acontecimento, nem como modelo a ser preservado. Mas o que se trata de "manter presente e guardar no espírito como aquilo que deve ser pensado" é a "questão mesma do acontecimento e do seu sentido" - a "questão da historicidade do pensamento universal" (Foucault, 1984c, p. 111).

Para poder compreender essa idéia de historicidade do pensamento na perspectiva de Foucault, enquanto articulada com a noção de acontecimento, é preciso, antes, caraterizar esta noção.

Se, em A arqueologia do saber e em Nietzsche, a genealogia e a história (Foucault, 1972; 1979), Foucault entende o acontecimento como a irrupção de uma singularidade única e aguda, no lugar e no momento de sua produção, no Theatrum Philosoficum (Foucault, 1980, p. 46-51), comentando Deleuze, vai definir o "sentido-acontecimento"como sendo "sempre tanto a ponta deslocada do presente como a eterna repetição do infinitivo". Neste sentido, no exemplo que toma: "morrer nunca se localiza na espessura de algum momento, antes a sua ponta móvel divide infinitamente o mais breve instante; morrer é muito mais pequeno que o momento de pensá-lo; e de uma outra parte desta hediondez sem espessura morrer repete-se indefinidamente. Eterno presente? Com a condição de pensar o presente sem plenitude e o eterno sem unidade: Eternidade (múltiplo) do presente (deslocado) (p. 48-49) ${ }^{3}$. É a partir dessa concepção que critica uma filosofia da história que "encerra o acontecimento no ciclo do tempo (...) converte o presente numa figura enquadrada pelo futuro e pelo passado; o presente é o anterior futuro que já se desenhava na sua própria forma, e é o passado por chegar que conserva a identidade do seu conteúdo. Precisa, pois, por um lado de uma lógica de essência (que a fundamenta na memória) e do conceito (que estabeleça como saber futuro), e por outro lado, de uma metafísica do cosmos coerente e acrescida, do mundo em hierarquia. Três filosofias, pois, que deixam escapar o acontecimento" (Foucault, 1980, p. 50).

Foucault caracterizando o ethos filosófico, como um pensamento critico que nos liga à Aufklärung, afirma que essa crítica, referindo-se então à sua própria atualidade, "se separará da contingência que nos fez ser como somos, [ levando-nos] à possibilidade de não sê-lo mais, de pensar e atuar diferente. Não é buscar tornar possível uma metafísica que finalmente se converte numa ciência, mas sim buscar dar novos ímpetos, tanto quanto seja possível, ao indefinido trabalho da liberdade". (Foucault, 1988, p.301) $)^{4}$.

Nesta passagem, o "sentido-acontecimento"poderia ser simultaneamente definido como o infinitivo acontecer da liberdade - "indefinido trabalho da liberdade"- e a "ponta deslocada do presente"- o "buscar dar novos ímpetos" ou o "relançar-se" da crítica no sentido de uma "apropriação" da liberdade enquanto possibilidade de "pensar e atuar diferente" do

${ }^{3}$ Destaques meus.

${ }^{4}$ Destaque meu. 
que pensamos e atuamos: uma reflexão sobre os "limites" de nossa finitude histórica. Neste sentido ainda, o acontecimento pode ser considerado como uma abertura de um campo de possibilidades: "qual o campo atual das experiências possíveis?"

Pode-se aproximar ainda a noção de acontecimento de Foucault à acepção que Deleuze dá a ela: de um "entre-tempo" como "espera e reserva" (Deleuze, 1993, p. 203-204), ou ainda como o "ins-tante" (Augenblick), como o conjunto de tudo o que do porvir e do vigor de ter sido se concentra e condensa na dinâmica de uma unidade (Heidegger, 1990, p. 197, 204).

Não se pode isolar, no entanto, a noção de acontecimento, da de problematização, nem da de atualidade. Pois como já se disse anteriormente, para Foucault, com Kant "a filosofia pela primeira vez problematiza a sua própria atualidade discursiva: atualidade que ela questiona como acontecimento, do qual ela pode dizer o sentido, o valor, a singularidade filosófica (...)" (Foucault, 1984c, p. 104). A problematização da atualidade como acontecimento constitui-se num certo movimento do pensamento, da crítica, que desatualiza o hoje, o presente, fazendo da atualidade uma "borda do tempo que envolve nosso presente, que o domina e que o indica em sua alteridade" (Foucault, 1972, p. 162-163).

A problematização, como crítica, se constituiria num certo "ethos filosófico", entendendo por ethos, no sentido grego: "uma atitude (...) uma maneira de relacionar-se com a realidade atual, a opção voluntária pela qual optam algumas pessoas e finalmente uma maneira de pensar e de sentir; uma forma de atuar e conduzir-se que ao mesmo tempo marca a relação de pertinência e de apresentação de si mesma como uma tarefa (...)" (Foucault, 1988, p. 295).

Se o que nos liga à Aufklärung é uma reativação permanente de "um ethos filosófico que poderia descrever-se como a crítica permanente de nossa era", compreende esse ethos como uma "atitude limite reflexão sobre os limites" no sentido de "transformar a crítica conduzida até agora na forma de uma limitação necessária, em uma crítica prática de uma transgressão possível" (Foucault, 1988, p. 298, 300). Se a "reflexão kantiana é ainda uma maneira de filosofar que não perdeu a sua importância ou efetividade durante os últimos dois séculos" a "crítica ontológica de nós mesmos não deve ser considerada somente como uma teoria, uma doutrina, nem sequer como um corpo permanente de conhecimentos que foram se acumulando; deve conceber-se como uma atitude, um ethos, uma vida filosófica onde a crítica ao que somos é ao mesmo tempo uma análise histórica dos limites que se nos impõem e um experimento que torna possível ultrapassá-los" (Foucault, 1988, p. 304)5.

Nessa linha de reflexão - sobre a problematização como acontecimento - talvez se possa indicar que aqui problematização seja um modo de apropriação do acontecimento pelo pensamento, através de um ques- 
tionamento da atualidade. A problematização constitui-se numa abertura do pensamento diante da abertura do acontecimento. Este movimento de apropriação do acontecimento pelo pensamento, é simultaneamente reserva - apropriação do já pensado - e espera - como o aguardar por todos os lados, no interior do já pensado, o não pensado ainda (Heidegger, 1958, p. 165). Esse movimento do pensamento, a problematização, é ainda $e x-$ perimento, no sentido antes indicado por Foucault, que se aproxima da perspectiva heideggeriana da experiência como aquilo que consiste em nos afetar e transformar (Figueiredo, 1994, p. 121). Neste sentido o pensamento é problematização e experimento (Deleuze, 1988, p. 124).

Assim é que para Foucault a tarefa desse ethos filosófico, da crítica, não é a de perseguir uma "continuidade meta-histórica através do tempo", nem suas "variações", mas a busca de "determinadas figuras históricas" e da "experiência que temos dela em nós mesmos", "através de certas formas de problematização". "O estudo dos modos de problematização (isto é, o que não é uma constante antropológica nem uma variação cronológica) é portanto uma maneira de analisar perguntas de importância geral em sua forma histórica única" (Foucault, 1988, p. 303-304 ) ${ }^{6}$.

A problematização é um trabalho interrogativo do pensamento: “O que é Aufklärung?"; "O que é a Revolução?"; "O que é que se passa hoje?” (Foucault, 1984c, p. 35); “O que é a crítica?” (Foucault, 1990, p. 35). Trata-se de "uma atitude filosófica [que] deve traduzir-se em um trabalho de diversas perguntas" (...) e "tem sua coerência teórica na definição de formas históricas únicas, onde as generalidades de nossas relações com as coisas, com os outros, com nós mesmos, foram problematizadas" (Foucault, 1988, p. 304). Quando Foucault incorpora a questão de Kant "o que é Aufklärung?" toda a sua interpretação é marcada pelas problematizações constituindo-se num "trabalho de diversas perguntas".

Aqui, também não é possível deixar de lado uma referência a Heidegger, quando ele diz que: "escrevo todas estas coisas em forma de perguntas, pois tanto quanto vejo, um pensamento não é hoje capaz de outro passo que não seja meditar insistentemente sobre aquilo que suscitam as interrogações levantadas" (Heidegger, 1969, p.38).

O trabalho interrogativo sobre a "herança" da Aufklärung, como já se disse anteriormente, não é o de preservá-la intacta, mas se trata, antes, de um certo modo de estar ligado à "tradição", em que a problematização através do pensamento é fundamental.

Como afirma Heidegger: “A tradição não nos entrega à prisão do passado (...). Transmitir, delivrer, é um libertar para a liberdade do diálogo com o que foi e continua sendo" (Heidegger, 1979b, p. 15). Ou ainda: "Que quer que pensemos e qualquer que seja a maneira como procuramos pensar sempre nos movimentamos no âmbito da tradição. Ela impera quando nos liberta do pensamento que olha para trás e nos libera para um pensamento do futuro. (...) Mas, somente se nos voltarmos pensando para o já pensado, sere-

\footnotetext{
${ }^{6}$ Destaque meu.

${ }^{7}$ Destaques meus.

${ }^{8}$ Destaques meus.
} 
mos convocados para o que ainda está para ser pensado" (Heidegger, 1979a, p. 187).

Na perspectiva de Foucault o trabalho interrogativo que caracteriza o ethos filosófico presente na crítica ontológica de nós mesmos, a partir da Aufklärung, consiste numa "prova histórico-prática dos limites que podemos ultrapassar [o experimento] e desta maneira como um trabalho levado a cabo por nós mesmos, sobre nós mesmos, como seres livres" (Foucault, 1988, p. 301). ${ }^{7}$ Um trabalho sobre "os 'limites contemporâneos do necessário', isto é, para aquilo que não é, ou já não é, indispensável para a constituição de nós mesmos como sujeitos autônomos" (Foucault, 1988, p. 298) . Nessa perspectiva, ainda, esse trabalho da crítica não busca as "estruturas formais como valor universal", mas sim "uma investigação histórica dos fatos que nos conduziram a nos constituirmos a nós mesmos e a nos reconhecermos como sujeitos do que fazemos, pensamos e dizemos" (p. 300) ${ }^{9}$.

A "herança" da Aufklärung inscrita na problematização que Foucault faz de sua própria atualidade, enquanto uma reativação através do pensamento da questão da autonomia e da liberdade do sujeito, questiona os limites do "estado de coisas" atual, a "finitude histórica" do seu presente. Neste movimento, a herança da Aufklärung é simultaneamente uma possibilidade herdada e escolhida. É através da escolha, que se manifesta no modo como a problematização da atualidade se propõe, que se dá a transmissão das possibilidades legadas, como aquilo que "permanece nos enfrentando" hoje. Nesse sentido a possibilidade é herdada porque ela é possível, mas só se torna efetiva a partir da decisão que a escolhe (cf. Heidegger, 1990, p. 189-190; 1964, p. 224).

Nesta direção pode-se acrescentar, ainda, um outro traço importante desse "ethos filosófico", como uma "crítica ontológica de nós mesmos". Esse ethos teria "sua coerência prática na inquietude que produz o processo de por à prova a reflexão histórico-crítica de práticas concretas. Não se deve dizer, hoje em dia, que esta tarefa crítica ocasiona confiança na Ilustração; mas continuo pensando que esta tarefa requer trabalhar sobre nossos limites, isto é, um trabalho paciente proveniente de nossa impaciência pela liberdade" (Foucault, 1988, p. 304) ${ }^{10}$.

Esta "inquietude" que se expressa na "impaciência pela liberdade" e que "produz o processo de por à prova a reflexão crítica de práticas concretas", enquanto uma "atitude limite", reativa a "herança" de um passado, como aquilo que permanece nos enfrentando como questão, e exige um "trabalho paciente" sobre "nossos limites", na direção de uma "transgressão possível" - a projeção de um campo de possibilidades.

É neste movimento de temporalização do pensamento, que revela uma certa concepção de historicidade, que Foucault formula a sua problematização sobre os gregos da Grécia clássica. É a partir dessa

9 Destaques meus.

${ }^{10}$ Destaques meus. "inquietude", como "impaciência pela liberdade" que ele problematizará os limites que a "problemática das liberações" coloca para a sua atualidade; 
quando indica que esta problemática está presa nos termos mesmos que o poder que ela denuncia lhe impõe. Neste sentido, como já se disse anteriormente, mas convém reafirmar, os gregos não se constituem em "valor exemplar", nem em "algo ao qual retroceder". Mas podem ajudar a constituir um "certo ponto de vista (...) para analisar o que está acontecendo agora - e modificá-lo" (Foucault, 1984e, p. 47-49).

Como afirma Deleuze, analisando Foucault: "Nenhuma solução pode ser transposta de uma época à outra, mas pode haver usurpações ou invasões de campos problemáticos, fazendo os 'dados' de um velho problema serem reativados em outros. (Talvez haja ainda um grego dentro de Foucault, uma certa confiança numa 'problematização' dos prazeres...)" (Deleuze, 1988, p. 122).

Nesse sentido, o que é reativado, da problemática grega, pela interrogação sobre os limites da "problemática das liberações" na atualidade, é o que Foucault chama "ética", entendida como "um domínio de si", "um tipo de relação que determina como o indivíduo se constitui como sujeito moral de suas próprias ações" (Foucault, 1984e, p. 51).

Como afirma F. Ewald, os últimos textos de Foucault - $O$ uso dos prazeres e $O$ cuidado de si (Foucault, 1984a; 1985) - apresentam uma inflexão importante em seu pensamento: passa da "problemática do governo dos outros à do governo de si mesmo". A sua análise indica "a maneira como o sujeito se constitui como sujeito em um campo onde ele é livre com relação a códigos e interdições, segundo os procedimentos de subjetivação que são os da ética". "Com a idéia do cuidado ético, de uma estética da existência, Foucault indica, hoje, uma maneira de sair dos impasses que continha a sua problemática das 'liberações"” (Ewald, 1984, p. 72-73).

É importante ressaltar, ainda, contra aquilo que se poderia considerar como um exacerbado individualismo que caracterizaria o último Foucault, que a sua problematização sobre a ética e a liberdade no pensamento grego, considera que esta liberdade "não é simplesmente refletida como a independência de toda a cidade. (...) A liberdade que convém instaurar é evidentemente aquela dos cidadãos no seu conjunto, mas é também, para cada um, uma certa forma de relação do indivíduo para consigo. (...) A atitude do indivíduo em relação a si mesmo, a maneira pela qual ele garante sua própria liberdade no que diz respeito aos seus desejos, a forma de soberania que ele exerce sobre si, são elementos constitutivos da felicidade e da boa ordem da cidade" (Foucault, 1984a, p. 73-74). Mais ainda, e de um certo modo relacionando a "problemática do governo dos outros à do governo de si mesmo" enfatiza que a liberdade "na sua forma plena e positiva (...) é poder que se exerce sobre si, no poder que se exerce sobre os outros; (...) quem deve comandar os outros é aquele que deve ser capaz de exercer uma autoridade perfeita sobre si mesmo". (...) "A temperança entendida como um dos aspectos de soberania sobre si é não menos do que a justiça, a coragem ou a prudência, uma virtude qualificadora daquele que 
tem a exercer domínio sobre os outros" (Foucault, 1984a, p. 75).

Para Foucault, ainda, a liberdade "que caracteriza o modo de ser do homem temperante não pode conceber-se sem uma relação com a verdade. Dominar os seus próprios prazeres e submetê-los ao logos, formam uma única e mesma coisa" (Foucault, 1984a, p.79). "Não se pode constituir-se como sujeito moral no uso dos prazeres sem constituir-se ao mesmo tempo como sujeito de conhecimento" (p. 80). Essa relação com a verdade se abre para uma "estética da existência". "Deve-se entender com isto uma maneira de viver cujo valor não está em conformidade a um código de comportamentos nem em um trabalho de purificação, mas depende de certas formas, ou melhor, certos princípios formais gerais no uso dos prazeres, na distribuição que deles se faz, nos limites que se observa, na hierarquia que se respeita. Pelo logos, pela razão e pela relação com o verdadeiro que a governa, uma tal vida inscreve-se na manutenção ou reprodução de uma ordem ontológica; e por outro lado, recebe o brilho de uma beleza manifesta aos olhos daqueles que podem contemplá-la ou guardá-la na memória" (Foucault, 1984a, p. 82).

Essa problematização da ética no pensamento grego, realizada por Foucault, capta aquilo que seria uma singularidade única: a problematização ética entre os gregos dava-se em domínios da vida em que imperavam a liberdade. Nestes domínios o homem grego tinha liberdade de decisão sobre suas ações. Neste sentido, "a liberdade não seria uma possibilidade ética entre outras mas a possibilidade mesma da ética" (Fonseca, 1994, p. 114).

Foucault, numa interrogação sobre a sua atualidade, que indica os "impasses da problemática das liberações" - os limites do pensamento no presente - neste mesmo movimento, nela reinscreve a problemática de uma ética da existência - e da liberdade - como acontecimento. Num "trabalho paciente proveniente de nossa impaciência pela liberdade", o trabalho da crítica, do pensamento, Foucault problematiza na sua atualidade a possibilidade do que seria "indispensável para a constituição de nós mesmos como sujeitos autônomos". E reativa, através deste trabalho, um certo modo de pensar a constituição do sujeito por si mesmo, como ser livre, e um certo modo de pensar a liberdade, como alguma coisa que permanece nos enfrentando, como questão, na atualidade.

Este acontecimento, re-inscrito na crítica ontológica da atualidade, pode ser entendido como uma "ponta deslocada do presente", na perspectiva de uma desatualização do hoje, (do presente). Nesse movimento a problematização da nossa atualidade configura-se como uma abertura do pensamento, que é simultaneamente reserva e espera - o re-colher do já pensado e a possibilidade que nos convoca a pensar sobre o não pensado

${ }^{11}$ Destaque meu. 
CARDOSO, Irene de Arruda Ribeiro. Foucault and the concept of event. Tempo Social; Rev. Sociol. USP, S. Paulo, 7(1-2): 53-66, october 1995.

ABSTRACT: Based on Foucault's last works, I intend to analyse the importance of his work about a history of thought in which the concept of event is important. Articulated with the concepts of actuality and of problematization it constitutes the means by which Foucault focuses what he calls an ontology of the present. Based on Kant he characterizes the philosophic ethos of the critique of the present, following this tradition in a specific way. By defining the questioning of actuality as a revival of the question of the Aufklärung, Foucault makes of it an event which, if conceived as a possibility of the constitution of ourselves, questions us as autonomous subjects. The question about the limits of the present and about the possibility of violationg them restores a problematic field of thought through concentrating on the problematic issue of autonomy and liberty. Starting from this field he formulates his question about the Greeks in Classic Greece, of ethics as a kind of relation which determines how the individual constitutes itself as a moral subject of his own actions.

ainda, no interior do já pensado.

Trata-se, como diz Foucault, interpretando o seu próprio trabalho, de uma "história do pensamento", que quer dizer "não simplesmente história das idéias ou das representações, mas também a tentativa de responder a esta pergunta: como é que um saber pode se constituir? (Foucault, 1984b, p. 75$)^{11}$.

Como afirma Deleuze: "certamente uma coisa perturba Foucault, e é o pensamento. 'Que significa pensar? O que se chama pensar?' - a pergunta lançada por Heidegger, retomada por Foucault, é a mais importante de sua flechas. Uma história, mas do pensamento enquanto tal. Pensar é experimentar, é problematizar" (Deleuze, 1988, p. 124).

Recebido para publicação em agosto/1995

\section{REFERÊNCIASBIBLIOGRÁFICAS}

Deleuze, Gilles \& Guattari, Felix. (1993) O que é a Filosofia? Rio de Janeiro, Editora 34. . (1988) Foucault. São Paulo, Brasiliense.

Ewald, François. (1984) Michel Foucault. In: Escobar, Carlos Henrique. Michel Foucault (1926-1984) - O Dossier - últimas entrevistas. Rio de Janeiro, Livraria Taurus Editora.

FigueIREDO, Luís Claudio. (1994) Escutar, recordar, dizer - encontros

UNITERMS:

event, history, actuality, problematization, present, liberty. 
heideggerianos com a clínica psicanalítica. São Paulo, Educ/ Escuta.

Fonseca, Márcio Alves. (1994) O Problema da Constituição do Sujeito em Michel Foucault. Mimeo. São Paulo, PUC.

Foucault, Michel. (1972) A arqueologia do saber. Petrópolis Lisboa, Vozes Centro do Livro Brasileiro.

. (1979) Nietzsche, a genealogia e a História. In:

Microfísica do Poder. Org. por Roberto Machado. Rio de Janeiro, Edições Graal.

. (1980) Nietzsche, Freud e Marx - Theatrum Philosoficum. Porto, Anagrama.

- (1984a) História da sexualidade II - O uso dos prazeres. Rio de Janeiro, Edições Graal.

. (1984b) O cuidado com a verdade. Ewald, François - Entrevista com M. Foucault, Le Magazin. In: EscoBAR, Carlos Henrique (org.). Michel Foucault (1926- 1984) - o Dossier - últimas entrevistas. Rio de Janeiro, Livraria Taurus Editora.

. (1984c) O que é o Iluminismo. In: Escobar, Carlos Henrique (org.). Michel Foucault (1926- 1984) - o Dossier - últimas entrevistas. Rio de Janeiro, Livraria Taurus Editora. Curso inédito de Michel Foucault no Collège de France, 1983. Transcrição de Katharina Von Bülow. Dossier Michel Foucault. Publicado originalmente Magazine Littéraire, 207, maio de 1984.

(1984d) O retorno da moral. Barbedette, Gilles e Scala, André. Entrevista de Michel Foucault. Les Nouvelles, em 29/5/1984. In: EscoBAr, Carlos Henrique (org.). Michel Foucault (1926-1984) - 0 Dossier - últimas entrevistas. Rio de Janeiro, Livraria Taurus Editora.

. (1984e) Sobre a genealogia da ética: uma visão do trabalho em andamento. Dreyfus, Hubert, L. e Rabinow, Paul. Entrevista e conversa com Michel Foucault em Berkeley, EUA, abril de 1983. In: EscoBAR, Carlos Henrique (org). Michel Foucault (19261984) - O Dossier - últimas entrevistas. Rio de Janeiro, Livraria Taurus Editora.

. (1985a) A história da sexualidade III - O cuidado de si. Rio de Janeiro, Edições Graal.

. (1985b) La vie: l'expérience et la science. Revue de Métaphysique et de Morale, $\mathrm{n}^{\circ}$ 1, jan/mars: 3-14.

. (1988) Que es la Ilustración? (Was ist Aufklärung?). Tradução de Rebeca Treviño. In: Sociologica. Mexico. Universidad Autonoma Metropolitana. Ano 3, n ${ }^{\circ}$ 7-8, mayo-deciembre. Originalmente publicado como What is Enlightenment? In: Rabinow, Paul. (1984) The Foucault Reader. New York, Pantheon Books. 